\title{
Las tareas del espíritu en José Martí: últimos días en campaña
}

\section{The Tasks of the Spirit in José Martí: \\ Last Days in Campaign}

\section{As tarefas do espírito em José Martí: últimos dias de campanha}

\author{
Mayra Beatriz Martínez \\ Investigadora \\ Centro de Estudios Martianos \\ Recibido: 4/8/2018 \\ Aceptado: 10/11/2018 \\ DOI: http: //doi.org/10.15359/tdna.35-65.10
}

\section{Resumen}

Los fundamentos en que se asienta la espiritualidad que expresan los textos de José Martí y que practicó en la vida, son los mismos que se convierten en herramientas para su proyecto liberador. Un repaso de sus textos y discursos, especialmente los correspondientes a su preparación de la Guerra de Independencia de 1895, permiten comprobarlo.

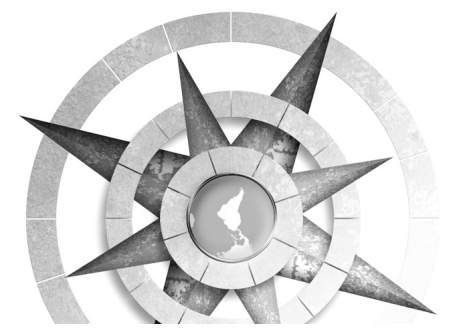

Keywords: Marti's thinking, spirituality, religiosity, masonry, "necessary war" 


\section{Resumo}

Os fundamentos sobre os quais se fundamenta a espiritualidade expressa nos textos de José Martí e que ele praticou na vida são os mesmos que se tornam ferramentas para seu projeto libertador.

Uma revisão dos seus textos e discursos, especialmente os correspondentes à sua preparação para a Guerra da Independência de 1895, permite-nos provar isto.

Palavras chave: Pensamento de Martí, espiritualidade, religiosidade, masonismo, "guerra necessária".

Unir los conceptos de "espiritualidad" y "religiosidad" en Martí tiende a ser controvertido y confuso a pesar de que destacados estudiosos como Fina García Marruz, Cintio Vitier, Reinerio Arce y Rafael Cepeda, por mencionar solo algunos autores de importancia, coloquen al Maestro mayormente en línea con el cristianismo. Tanto una como la otra -espiritualidad y religiosidad-, responden a un particular posicionamiento humano ante el mundo, que no necesariamente ha de guardar relación con algún sistema de culto, entendido como cuerpo de prácticas rituales predeterminadas, indispensables para poner al hombre en contacto con lo que se considere sagrado. Ello contrastaría, de forma inevitable, con el conocido antidogmatismo martiano, que habría de expresarse en buena cantidad de textos a lo largo de toda su vida, entre los cuales sobresalen, obviamente, aquellos donde asume una mirada crítica al evaluar a la iglesia católica, pero, de igual forma, en los que arremete contra la rigidez de las prácticas masónicas contra el secretismo, en particular- a pesar de que, como se sabe, pertenecía a esa institución fraternal.

Me inclino a entender la espiritualidad martiana -que, explícitamente, lo alentaría a proponer un nuevo tipo de religión-, más bien, desde el punto de vista sociológico, es decir, en lo relativo a su actividad social dentro del grupo humano: como fe, pero no intangible y personal, sino en tanto sentimiento de entrega a un ideal que, de manera efectiva, erige como sagrado: la justicia concreta para todos los hombres durante la propia vida, no postergable para un momento ulterior y de carácter divino. ${ }^{1}$ Martí propone una concepción moral del mundo renovada, a materializarse en realización social. Su tan abordada "nueva religión" habría de representar, pues, una expresión cuasi metafórica:

1 De mucho interés resulta la forma en que Arce, uno de los defensores de la filiación cristiana de Martí, enfoca su espiritualidad como parte de una especie de "cristianismo comunitario comprometido en la lucha por la paz y la justicia". Considera que "[...] lo que da unidad a lo religioso, lo ético y la práctica política y social es su doctrina del amor que, al mismo tiempo, constituye una de las piedras angulares de religiosidad y se constituye en la norma para medir éticamente toda acción política y social" (Arce, R. 1996: p. 136).
130 Las tareas del espíritu en José Martí: últimos días en campaña Mayra Beatriz Martínez

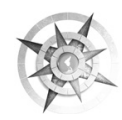


supone la devoción por el logro del bien colectivo. Los pilares en que se asentaría la espiritualidad que practicó en la vida, son los mismos que se convierten en herramientas para su labor emancipadora, para su proyecto liberador: el ejercicio de las virtudes útiles.

De ahí que, aunque Martí se auto identifique en muchos de sus textos con los estereotipos del Jesús -que divulga su evangelio- o del Crucificado - martirizado hasta la muerte por su fe-, representativos de valores y normas de comportamiento que, por demás, prescribe como parte de deberes ser que propone para hombres y mujeres nuestramericanos, habríamos de entender que su afinidad correspondía con el Jesús revolucionario - no con Dios encarnado en la tierra-; con el héroe que debió representar en su existencia histórica.

Las idea del ejercicio virtuoso y el holocausto útil, centrales para Martí, responderían al cumplimiento de un empeño que solo resultaría trascendente en la medida en que se articulara a las expectativas y al real bien de todos. En tal sentido, ese Cristo-Dios al que aludiera en cuaderno de apuntes fechado entre 1886 y 1887 muy significativamente como "el hombre de mayor idealidad del Universo” (Martí, 1975, p. 344)-y destaco el apelativo "hombre"-, se toca, en su vocación de servicio con otro de los paradigmas que hallaremos subsumido en sus textos: el del Quijo- te, cuyas acciones caballerescas, aunque puedan juzgarse alucinadas, también se encaminan al bien de los demás; a deshacer entuertos.

La apropiación de esos modelos sabemos que no es exclusiva, sino presente en un sinnúmero de obras literarias de diferentes ámbitos. De modo semejante, ha de comprenderse que lo asume, en particular, de la simbología bíblica y el tono mesiánico característicos de la tradición cristiana, a lo que habría de sumarse, tanto en sus textos como en su oratoria, un reiterado uso de alegorías de procedencia masónica. Su espiritualidad acendrada se afinca bastante en este tipo de repertorio tropológico, enraizado en la retórica cristiana o de la masonería, lo cual se torna, a su vez, esencial en su poética.

Si en Versos sencillos de 1891 -por solo poner un ejemplo anterior-, define específicamente el sentido que atribuye a la vida humana y, dentro de ella, al sacrificio como redención mayor -recordemos: "Cuando al peso de la cruz/ el hombre morir resuelve,/ sale a hacer bien, lo hace y vuelve,/ como de un baño de luz"- (Martí, en Obras Completas Edición Crítica, 2007: p. 331)², lo ratificaría con insistencia en variedad de textos durante los últimos meses de vida. Lo expresa a Gonzalo de Quesada, destacándolo como empresa humana

2 En lo adelante OCEC por Obras completas. Edición crítica. 
cotidiana, en misiva fechada $1^{\text {ro }}$ abril de 1895 -su testamento literario-, que fuera enviada todavía desde Dominicana: "En la cruz murió el hombre un día, pero se ha de aprender a morir todos los días" (Martí, p. 28) -y observemos como insiste en el apelativo "hombre" para Jesús-. Desde territorio baracoeso, el 15 de abril, en carta dirigida, entonces, de conjunto, a Gonzalo y a Benjamín Guerra, describe el gozo que experimenta al sumarse a la guerra, tras haber cargado como cruz el pecado de no haber participado en las campañas anteriores, al tiempo que se identificaba implícitamente, una vez más, con la imagen de Cristo-héroe, entrañable con sus prójimos. Asimismo, volvía a mencionar la iluminación, con lo que superponía connotaciones masónicas -la luz como triunfo que se alcanza tras difícil ascenso; la luz que el hombre debe atraer hacia sí para, a su vez, iluminar con ella-: "Hasta hoy no me he sentido hombre. He vivido avergonzado, y arrastrando la cadena de mi patria, toda mi vida. La divina claridad del alma aligera mi cuerpo". (Martí, en OCEC, t. 4, pp. 124-125)

Escribe ese propio día a Tomás Estrada Palma -hermano masón, como lo fueran Benjamín y Gonzalo-, y en su fervorosa misiva se percibe esa huella: "[...] al fin me he sentido entero y feliz [...] Ya entró en mí la luz, Estrada, y la salud que fuera de este honor buscaba en vano. El honor es la dicha y la fuerza."
Se alejaba cada vez más de las pasiones mundanales, se abría a la percepción de su luz interior: vencía lo espiritual, lo eterno, sobre lo perecedero.

Como parte del sustrato cristiano inmanente en su pensamiento, hemos de considerar lo que, de forma acertada, Rafael Cepeda (s/f, p. 74) ha señalado respecto al empleo martiano del concepto "alma", que encierra "connotaciones bíblicas y teológicas" Según Cepeda, "Martí identifica alma y espíritu" (p. 74).

Habría que tener en cuenta que, para los masones existe distingo: alma y espíritu cuentan por separado entre los elementos naturales propios de los seres animados, junto a materia, fuerza y vida, y, como tales, los advertimos en ocasiones. La realidad es que eran términos que manejaba con mucha frecuencia y, por momentos, podríamos estimar indistintos. Lo indiscutible es que su uso se conciliaría, muy especialmente, con lo político.

La connotación sociológica de la espiritualidad martiana -como forma de sentir y practicar su sistema de creencias- se expresó en documentos de muy diversa índole, para nada ligados estrictamente a la religiosidad o la masonería. Se percibe en documentos íntimos y en los dados a la publicación; en prosa y verso; en textos ubicables en los más diversos géneros... pero, muy en particular, en aquellos dedicados a 
su labor de propaganda revolucionaria y preparación de su "guerra necesaria" -tal como aludió la contienda bélica que juzgaba indispensable para el logro de la independencia patria.

Avanzar en el rastreo de tales marcas entre las ideas que manifiesta en sus últimos meses de vida, y que no fueron otra cosa que continuidad de inquietudes y criterios acrecentados y perfilados a lo largo de su existencia, no es difícil, a pesar de que se plasmen en escritos disímiles, como sus Diarios de campaña finales -que tomaremos como foco temático principal-, ${ }^{3}$ cartas a amigos, familiares y colaboradores e, inclusive, documentos directamente relacionados con la planificación y la política de la guerra. En todos, encontramos expresadas semejantes virtudes ligadas al crecimiento espiritual. Sería bien explícito al respecto en carta a Maceo de 1894: "Yo no mudo de alma, sino que la voy enriqueciendo con cuanto veo de grande y hermoso". (Martí, 2007, en OCEC, t. 3, p. 210).

En torno al tema, diría a Gonzalo y Benjamín (Martí, 2007, en OCEC, t. 4, p. 129), ya desde la manigua, refiriéndose al afianzamiento de ese proceso personal en circunstancias donde con-

3 Las ediciones en que he trabajado Diarios de campaña (críticas en 1996 y 2007; anotada en 2014) reúnen los antes denominados "Páginas de un diario" o "De Montecristi a Cabo Haitiano" y "Diario de campaña” o "De Cabo Haitiano a Dos Ríos". firmaba que la fraternidad era indispensable y su tarea, afianzarla: "El alma crece y se suaviza en el desinterés y el peligro". Y a Carmen Mantilla (OC, t. 20, p. 237): "Voy regando almas buenas, y noto cómo crece a veces el alma a los que me oyen. Es que sufrían de desamor, y oyéndome, creen [...]". Y, a Manuel Mercado, en su última misiva (OC. t. 20, p. 161-163): "[...] siento en la benevolencia de las almas la raíz de este cariño mío a la pena del hombre y a la justicia de remediarla”. En sus Diarios... se refiere así a los hombres virtuosos que va aunando: "Vamos haciendo almas" (2007: en Martínez, Edición Crítica, p. 91).

En consonancia, aparecerían adjetivaciones y metaforizaciones alusivas a las virtudes espirituales, mediante términos recurrentes como pureza, limpieza, luz, estrella, perfección... que se tocan, en gran medida, por demás, con el ideal de auto- perfeccionamiento masónico a través del cultivo de las virtudes -la tarea incesante de los hermanos: "pulir su piedra bruta".

Por solo citar algunas referencias a valores vinculados con la superioridad espiritual, que pueden percibirse en hombres y mujeres retratados en sus Diarios... -y expresarse, incluso, de forma tangencial, en la caracterización de elementos contextuales que los rodean-, hallamos menciones a "la casa pura de Nicolás Ramírez" (2007: p. 18) médico 
coronel camagüeyano, veterano de los Diez Años, quien lo acoge en Santiago de los Caballeros; a "el batey limpio de Manuel Boitel [...]”, (p. 26) carpintero cubano de nacimiento y a su "casa pulcra”. (p. 27).

De igual manera, alude a la propia población de Santiago de los Caballeros, destacando que es "trabajadora y épica" -por lo tanto, virtuosa-y anota además: "Hablamos de las casas nuevas de la ciudad, y de su construcción apropiada, de aire y luz". En jornada, refiere que el canario Joaquín Montesinos -quien había sido compañero de su presidio juvenil en La Habana y que entonces se encontraba asentado en Dominicana- le entrega "pan puro" para el camino (p. 39). De paso por Fort Liberté, en la casa de Nephtalí Reyes, masón haitiano que le diera asilo por una noche, refiere: "[...] la gallera está como una joya, de limpia y barrida [...]. (p. 49). Y compara con "un cestón de sol" al modesto pero alegre caserío de Petit Trou, donde es acogido amablemente por la gente más humilde: van ellos "planchados y lucientes", al festejo popular que "está en el sol, que luce como más claro y tranquilo" (p. 50).

Cuando menciona a Periquito Pérez, teniente coronel en la Guerra Grande y primer alzado en Guantánamo del 95 -según cuenta el propio Martí con admiración-, vuelve a atribuirle la virtud que en él percibe a un elemento que concurre en su entorno: "Él no quiere gente a caballo, ni monta él, ni tiene a bien los capotes de goma, sino la lluvia pura, sufrida en silencio" (p. 106).

Para destacar la importancia del trabajo infinito en pos del logro de una ética elevada y la inconveniencia de cejar en esta tarea, cita a Gómez en la primera parte de sus Diarios... - correspondiente a su ruta por Dominicana y Haití-. Hablan en torno a un viejo militar veterano, que se sobrepone a las terribles heridas dejadas en él por la guerra: "[...] el General dice esta frase, que es toda una teoría del esfuerzo humano, y de la salud y necesidad de él:-'El caballo se baña en su propio sudor.'-Eusebio vive de puro hombre [...]" (p. 19). En esta misma sección de sus Diarios..., recoge lo que comentan sobre don Jesús Domínguez, un cultivador de tabaco vecino de Gómez: "[...] cuando se le acaba la fortuna sigue con la cabeza alta, sin que le conozca nadie la ruina, y a la tierra le vuelve a pedir el oro perdido, y la tierra se lo da: porque el minero tiene que moler la piedra para sacar el oro de ella [...] (p. 22).

De manera diáfana, sus anotaciones de la jornada del 3 de marzo, insisten en que lucha contra de las tendencias innobles del hombre ha de ser incansable. Reflexiona en torno a la inconveniencia de que el hombre ceda a "la gran tentación", a "la satisfacción de las necesidades sin el esfuerzo original [que] desata y desenvuelve al hombre, y lo cría"; que la

134 Las tareas del espíritu en José Martí: últimos días en campaña Mayra Beatriz Martínez 
paz es "solo asequible cuando la suma de desigualdades llegue al límite mínimo en que las impone y retiene necesariamente la misma naturaleza humana". Concluye: "Es inútil, y generalmente dañino, el hombre que goza del bienestar de que no ha sido creador (p. 56). De interés mencionar cómo vincula perfeccionamiento y creación.

Poco después, conocido ya el alzamiento del 24 de febrero, que se ha producido en Cuba, es de imaginar el estado de impaciencia de Martí: aún no tienen una vía cierta para hacer llegar la expedición que preparan a la Isla, ni tampoco cuenta con las armas previstas. De momento, no puede hacer lo que corresponde y anota con pesar: "Duerme mal, el espíritu despierto. El sueño es culpa, mientras falta algo por hacer. Es una deserción” (p. 53).

No solo aparece implícito el ideario de la masonería en los diarios en lo relativo a sus principios básicos. También pueden identificarse emblemas tomados de su simbología particular en narraciones, descripciones y reflexiones. Tal ocurre respecto a su relato de un enigmático sueño que solo podría leerse bajo el prisma de la necesidad del pulimento constante de la piedra bruta, de la depuración virtuosa:
Soñé que, de dos lanzas que había, sobre la lanza oxidada no daba luz el sol, y era un florón de luz, y estrella de llamas, la lanza bruñida. Del alma perezosa, no se saca fuego.- Y admiré, en el batey, con amor de hijo, la calma elocuente de la noche encendida, y un grupo de palmeras, como acostada una en la otra, y las estrellas, que brillaban sobre sus penachos. Era como un aseo perfecto y súbito, y la revelación de la naturaleza universal del hombre.-(p. 31-32).

Sugiere que la perfección espiritual a que aspira - "la lanza bruñida"- debe afianzarse, sobre todo, en el amor como arma para el bien colectivo. Sin embargo, no renuncia a la "estrella de llamas", correspondiente a la "flamígera” masónica, símbolo de la virtud mágica y cuya fuerza terrible estriba en la inteligencia que la dirige. Representa la resurrección, el triunfo sobre las tinieblas: es, sin dudas, "la estrella que ilumina y mata" de los versos martianos ${ }^{4}$ y la que debe asistir su tarea revolucionaria. $\mathrm{Al}$ propio tiempo, menciona en su descripción onírica a estrellas de otra índole,

4 En "Yugo y estrella" (2004: p. 143): Se dice que con su resplandor guía al masón a través de las oscuras sendas de la ignorancia, de la superstición y de las falsas ideas, para que pueda superar los escalones que llevan al interior del templo, que simbolizan inteligencia, rectitud para obrar, valor, prudencia y amor a la humanidad suficiente para el sacrificio.

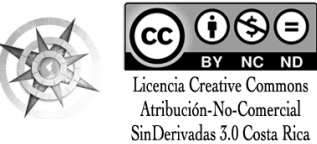


semejantes, entonces, más a las apacibles quinarias de la masonería, alegorías, precisamente, del amor fraternal. A la altura de 1894, Martí había sido terminante al respecto uniendo tales extremos aparentemente contrapuestos: "Sólo el amor construye. Hiere, y saca sangre a los hombres, para amasar con ella los cimientos de su felicidad. (Martí, en OC, t. 5, 2007:, pp. 243). Recomienda al amor en tanto profesión de fe y, asimismo, lo considera vigoroso instrumento para un buen gobierno, justo en momentos en que inicia la organización de su "guerra necesaria" y delinea su utopía de república.

Un borrador que se presume corresponde a la preparación de una intervención pública de estos últimos años de organización de la guerra, alude claramente a esa estrategia, cuando se refiere a la "levadura de toda el alma cubana del destierro", a su labor de alimentar la fusión política entre los emigrados, y legitima a la par "el espíritu que unifica y el machete que pelea" (Martí, 2007, en OC: t. 4, p: 336).

En discurso en el Hardman Hall, Nueva York, 1892, había afirmado: "[...] el amor, administrado por la vigilancia, es el único modo seguro de felicidad y gobierno entre los hombres [...]". (OC, t. 4, p. 301) Y en 1893, en carta a José Dolores Poyo:
Lo que hemos hecho, el espíritu de lo que hemos hecho, la religión de amor en que el alma cubana está fundiendo sus elementos de odio, eso amparará mañana a los mismos, soberbios o ciegos, hombres de miedo y de alquiler, hombres arrimadizos y segundones, hombres destructivos y nulos, hombres ornamentales o insolentes [...]. (en OC, t. 2, pp. 462-463)

A finales de abril de 1895 y en carta a un comandante de la contienda, Luis Rivera, escrita desde el propio campamento general en campaña y contemporánea a las páginas finales de sus Diarios..., invita a los combatientes -que presupone virtuosos y sacrificados, aunque rudosa compartir, sin menoscabo de su hombría, los lujos del espíritu: "La vida de la libertad afina en el hombre los sentimientos delicados, y de éstos ninguno es más bello que la simpatía de las ideas generosas entre dos hombres capaces de amar la virtud y el sacrificio" (en OC, t. 4, p. 142). De semejante naturaleza sería la "delicada honestidad" que permea su relación de siempre con el "hermano queridísimo", Manuel Mercado, a quien en su última carta inconclusa, el día antes de morir, le cuenta con qué "ternura y agradecimiento y respeto" (OC, t. 20, p. 161-164) lo quiere -un documento hermoso, de fineza exquisita, considerado, significativamente, su testamento político. 
La virtud espiritual como ideal patriótico es motivo que trasversaliza un documento de índole tan visceralmente política como "El Partido Revolucionario Cubano a Cuba" -llamado "Manifiesto de Montecristi"-, que firma junto al Mayor General de la contienda recién iniciada, Máximo Gómez, como se sabe, también masón. Por solo mencionar un fragmento, recuerdo cómo alude a los combatientes viriles que se suman a la lucha. Los califica como "[...] elementos expertos y novicios, por igual, movidos de ímpetu ejecutivo y pureza ideal, que, con nobleza idéntica, y el título inexpugnable de su sangre, se lanzan tras el alma y guía de los primeros héroes, a abrir a la humanidad una república trabajadora [...]" (Martí, 1985: p. 24)

Los retratos de patriotas y de pobladores, que colaboran con los preparativos o luego los apoyan en la manigua, siendo de razas diversas, de procedencia social disímil, gozan del privilegio de la belleza. Descripciones que, sin esas pinceladas que destacan su perfección espiritual, podría tornarse, cuando menos, semblanzas elogiosas, pero de seres físicamente comunes. Sin embargo, podemos percibir el eje belleza-virtud que los signa.

De Paquito Borrero, por ejemplo, apenas menciona "su cabeza santa y fina [...]”.(Martí, 2007e, p. 26) Luis González Pineda -quien había reunido 17 hombres para que les acompañaran y ha llamado antes, "dueño y alma del pueblo de San Antonio"- interpela a Martí antes de despedirse y él lo recoge en su diario. Cito: " 'Ese rostro [el de Martí] quedará estampado aquí.' [¿en su mente; en su corazón?, nos preguntamos...] Y me lo decía con rostro celeste". (2007e, p. 28). No son pocos sus bosquejos de hombres y mujeres virtuosos en los que destaca esa belleza especial en particular, en combatientes negros-. Volvemos a su descripción del anciano González Pineda, para ejemplificarlo: "Bello, el abrazo de Luis, con sus ojos sonrientes, como su dentadura, su barba cana al rape, y su rostro, espacioso y sereno, de limpio color negro. [...] De la paz del alma viene la total hermosura a su cuerpo ágil y majestuoso”. (p. 94)

Importante es tener en cuenta lo que García Marruz refiere respecto al sentir amoroso martiano por sus iguales -de fundamento crístico por supuestocomo camino de realización humana:

El amor no tiene en Martí un fundamento psicológico sino cosmogónico. En el universo todo es análogo, todo se corresponde -el orden de la naturaleza, el orden humano-, no por derivación unilateral sino por tener una raíz común en el amor. Él es fuente de vida y la única fuerza capaz de conducir la a su final realización. (García Marruz , 2003: 304) 
En efecto, se produce un enlace evidente en el pensamiento martiano entre las virtudes humanas y el universo natural, cuya juntura principal vendría de la irradiación del amor. El hombre no alcanza su mayor estatura sino en su relación cercana y fraterna con lo natural. Es lo que permite su reencuentro con el espíritu universal.

En la rememoración que hace en sus Diarios... del traslado de la pequeña partida, a pie, a tientas, en medio de la noche, desde la ciudad de Montecristi a la costa desde donde debería embarcarse la expedición -compuesta por Martí, Gómez, César Salas, Ángel Guerra, Paquito Borrero y Marcos del Rosario-, considera de interés insertar el retrato de un hombre que vislumbra, como una revelación, al abrirse finalmente el monte y dar con la orilla de la playa. Parece haber sido un guardia al que deben desarmar y maniatar -según testimonio que introduce Gerardo Castellanos en su libro Francisco Gómez Toro-. Pero Martí no hace esa mención pueril; rescata su propia visión, acentuando el sentido trascendente que es capaz de percibir en la escena. Oigámoslo: "De pie, a las rodillas el calzón, por los muslos la camisola abierta al pecho, los brazos en cruz alta, la cabeza aguileña de pera y bigote, tocada del yarey, aparece impasible, con la mar a las plantas y el cielo por fondo, un negro haitiano.-El hombre asciende a su plena beldad en el silencio de la naturaleza" (p. 66).
La posibilidad de comunicación del hombre con lo sagrado - no en la esfera de lo abstracto- la encuentra, pues, en la comunión concreta con lo natural, que entiende como la más cercana representación dable al humano de lo trascendente: del uni-verso, del versus uni que menciona en sus cuadernos de apuntes; de lo vario en lo uno. Es una exploración emocional que se trasluce desde su juventud y a lo largo de toda la literatura vinculada a sus experiencias de viajero, lo cual representa, desde luego, parte indispensable de su proceso cognoscitivo de nuestra América.

En uno de sus cuadernos de apuntes, atribuido a 1894, hallamos una anotación que hace bajo la influencia de la obra de Ralph Waldo Emerson. La termina refiriéndose a los pocos momentos que tiene el hombre en su vida "de dicha absoluta, dicha pura, que son los de pleno desinterés, los de confusión del hombre con la naturaleza [y continúa] (Emerson. La tarde de Emerson: Cuando pierde el hombre el sentido de sí, y se transfunde en el mundo)" (Martí, 1975, en OC, t. 21, p. 387). Mucho antes, en 1882, precisamente en la semblanza que le había dedicado al estadounidense tras su muerte, adelantaría: "La naturaleza inspira, cura, consuela, fortalece y prepara para la virtud al hombre. Y el hombre no se halla completo, ni se revela a sí mismo, ni ve lo invisible, sino en su íntima relación con la naturaleza". (Martí, 2004, en OCEC, t. 9, p. 330). 
No ha de considerarse raro, pues, que desde tierra dominicana, en sus Diarios..., comente como en éxtasis: "A la vaga luz, de un lado y otro del ancho camino, era toda la naturaleza americana: más gallardos pisaban los caballos en aquella campiña floreciente, [...] De autoridad y fe se va llenando el pecho". (Martí, 2007e, en OCEC, p. 30) Y, en Cuba, lo absorbe la contemplación de la noche en la manigua y tiene lugar uno de los momentos culminantes de sus páginas últimas:

La noche bella no deja dormir. [...] entre los ruidos estridentes, oigo la música de la selva, compuesta y suave, como de finísimos violines; la música ondea, se enlaza y desata, abre el ala y se posa, titila y se eleva, siempre sutil y mínima: es la minada del son fluido: ¿qué alas rozan las hojas? ¿qué violin diminuto, y oleadas de violines, sacan son, y alma, a las hojas? ¿qué danza de almas de hojas? (2007: p. 89).

Son muchas, desde luego, las coincidencias del pensamiento martiano respecto a la relación del hombre y su medio con las cosmovisiones de pueblos antiguos de todo el mundo; pero, sobre todo, de las culturas orientales y de las originarias de América que pudo conocer al paso o estudiar más adelante, y que debieron dejar su huella. Era conocedor de las doctrinas taoístas, cuyos principios consideraban que la naturaleza era el medio desde donde el hombre puede desarrollar sus más elevadas virtudes. Recuerdo, por ejemplo, cómo se reflejaba ese conocimiento y aceptación en su crónica acerca de un funeral de un ilustre chino, masón por más señas, personalidad destacada en los Estados Unidos, de 1888. Allí afirmaría: "Tao dice que no se ha de pisar un insecto ni cortar un árbol, porque es destruir la vida" (Martí, 2003, en OC, t. 12, p. 79).

Instruiría sobre ello, incluso, a niños y niñas, en su revista La Edad de Oro. Les hablaba, por ejemplo, del modo de vida de los anamitas - hoy vietnamitas-y se refería a su peculiar visión de la reencarnación. Les contaba que a ellos "[...] no les parece que la vida es propiedad del hombre, sino préstamo que le hizo la naturaleza, y morir no es más que volver a la naturaleza de donde se vino, y en la que todo es como hermano del hombre [...]". (Martí, 2007, La Edad de Oro, en OC, t. 18, p. 464).

Insistió en destacar la particular energía que procede de esa relación con el orden natural desde otro de sus cuadernos de apuntes, fechado por aproximación, 1886. "Hay algo de sagrado, en estos hombres producidos originalmente por la tierra en que habitan".(Martí, 2007, en OC, t. 21, p. 289). Resulta sumamente revelador que en su última carta conocida a su niña María Mantilla, fechada el 9 de abril de 1895, escrita en tierra cubana, elija destacar, justamente 
como una de sus últimas enseñanzas, la trascendencia de la unidad del hombre con la naturaleza:

Donde yo encuentro poesía mayor es en los libros de ciencia, en la vida del mundo, en el orden del mundo, en el fondo del mar, en la verdad y música del árbol, y su fuerza y amores, en lo alto del cielo, con sus familias de estrellas, -y en la unidad del universo, que encierra tantas cosas diferentes, y es todo uno [...]. (Martí, 2007, en OC, t. 20. p. 218)

Esta especial relación con el medio que, a lo largo de sus rutas por nuestra América, reconoció como práctica cotidiana entre aquellos que llamaría "hombres naturales"-mayormente pertenecientes a pueblos que denomina, a su vez, "originarios"-, por fuerza quedaría imbricada a otra virtud concomitante con la fraternidad a que aspiraba y que marcaría su propio enfoque ante la diversidad universal: el respeto. Con respeto y con verdadera devoción, narra en sus Diarios... una vivencia excepcional -que no comprende, pero que no vacila en enaltecer-, experimentada durante uno de sus traslados por mar de Cabo Haitiano a Montecristi. La relata, pues, desde su habitual perspectiva desprejuiciada y obviamente fascinado con fecha 4 de marzo:
Y abrí los ojos en la lancha, al canto del mar. El mar cantaba. Del Cabo salimos, con nubarrón y viento fuerte, a las diez de la noche; y ahora, a la madrugada, el mar está cantando. [...] que hoy es día de baile voudou, en el fondo de la mar, y ya lo sabrán ahora los hombres de la tierra: que allá abajo están haciendo los hechiceros sus encantos. La larga música, extensa y afinada, es como el son unido de una tumultuosa orquesta de campanas de platino. Vibra igual y seguro el eco resonante. Como en ropa de música se siente envuelto el cuerpo. Cantó el mar una hora, más de una hora. La lancha piafa y se hunda, rumbo a Montecristi. (Martí, 2007i, en OC, p. 59-60)

Quizás, todo lo esbozado hasta ahora permita reconocer que para Martí, la guerra de independencia que preparara fue una obra espiritual, tanto por los medios que utilizara para organizarla como respecto a los objetivos previstos para ser cumplidos dentro de la república que imaginara. En Patria, en 1892, afirmaría rotundo: "La guerra es [...] la forma más bella del sacrificio humano". (Martí, 2007, en OC, t. 1, p. 315). Así, el sentimiento de bienestar aunado al logro de la liberación $-\mathrm{O}$, al menos, estar en camino a ello- representaba claramente para él una experiencia netamente del alma, en tanto consideraba 
la libertad condición indispensable al devenir del espíritu universal, tal cual sostienen los postulados masónicos. En términos muy semejantes empleados dentro de la fraternidad, había justificado la sacralidad de la obra revolucionaria, en una de sus colaboraciones anteriores a La Nación:

La política es un sacerdocio, cuando empujan a ella gran peligro patrio, o alma grande. Hay criaturas que se salen de sí, y rebosan de amor, y necesitan darse, y traen a la tierra una espada invisible, siempre alta en la mano, que enciende con su fulgor los campos de batalla, mientras viven, y cuando caen en tierra cubiertas de toda su armadura, vuela cual llama azul, al sol. (Martí, 2007, en OC, t. 9, p. 355).

Había escrito, a este tenor, al Generalísimo, Máximo Gómez, en 1884: "Si la guerra es posible, y los nobles y legítimos prestigios que vienen de ella, es porque antes existe, trabajado con mucho dolor, el espíritu que la reclama y hace necesaria: y a ese espiritu hay que atender [...]". (Martí, 2007, en OC, t. 1, p. 178) Es esa certeza la que prima tanto en algunas de sus últimas cartas como en las páginas de sus Diarios... Así, el 18 de febrero de 1895, mientras viaja con Gómez para reunirse de nuevo con Mayía Rodríguez y Eleuterio Hatton, y definir detalles de la partida hacia Cuba, escribe esperanzado: "Nos rompió el día, de Santiago de los Caballeros a la Vega, y [dice] era un bien de alma, suave y profundo, aquella claridad".(pp. 29-30). Lo expresaría en el período en que, al fin, se encuentra en la manigua, como sensación de plenitud, nunca antes vivida. La noche en que pernoctan en Arroyo Carlos, después de encontrarse al fin con la pequeña partida con la tropa del comandante baracoeso Félix Ruenes, tras el desembarco, comenta: "[...] en todo el día, iqué luz, qué aire, qué lleno el pecho, qué ligero el cuerpo angustiado!"(p. 85). De igual modo, describe a su compañera de los años neoyorkinos, Carmen Miyares, su estado anímico al sumarse a la mambisada como la culminación de un camino iniciático: "Es muy grande, Carmita, mi felicidad, sin ilusión alguna de mis sentidos [...] puedo decirte que llegué al fin a mi plena naturaleza, y que el honor que en mis paisanos veo, en la naturaleza que nuestro valor nos da derecho, me embriaga de dicha, con dulce embriaguez" (Martí, en OC, 2007, tomo 20, p. 224).

El 28 de abril, al rememorar en sus Diarios... el tercer discurso que pronuncia en campaña -esa vez en el campamento de Vuelta Corta-, anota exaltado, subrayando la luminosidad que lo rodea: "Yo hablo, al sol. Y al trabajo. A que quede ligada esta fuerza en el espíritu unido: a fijar, y dejar ordenada, la guerra enérgica y magnánima [...]". (Martí, 
2007 m, p. 106). Nada menos que en una circular enviada a los jefes militares de los distintos departamentos, desde el Cuartel General en Campaña, advertiría: "La guerra por la independencia de un pueblo útil y por el decoro de los hombres vejados, es una guerra sagrada, y la creación del pueblo libre que con ella se conquista es un servicio universal". (Martí, 2007, en OC, t. 4, pp.136-137). Sin embargo, brota súbitamente en Diarios... - de manera muy evidente- una inquietud personal por la posible pérdida de sensibilidad humana, de valores espirituales, que podría sobrevenir al calor de la violencia desatada. El siguiente fragmento, sintomático de sus íntimas vacilaciones, se repite de forma casi exacta, en carta a Carmita Miyares, lo que revela la enorme preocupación que lo embargaba en ese momento. Escribe angustiado, inmediatamente después del famoso combate de Arroyo Hondo, a cuyas inmediaciones la partida de expedicionarios llega a acercarse poco antes de concluir: "[...] icómo no me inspira horror, la mancha de sangre que vi en el camino? ini la sangre a medio-secar, de una cabeza que ya está enterrada, con la cartera que le puso de descanso un jinete nuestro?" (p. 120)

Sin embargo, corren sus últimos días y en sus anotaciones correspondientes a la jornada del 14 de mayo -apenas cinco días antes de entrar él también en combate y, con ello, en la inmortalidad-, hallamos el retorno de su total seguridad respecto a la naturaleza del futuro por el que había venido trabajando y la justeza de los medios para alcanzarlo: "[...] a campo libre, la revolución entraría naturalmente, por su unidad de alma, en las formas que asegurarían y acelerarían su triunfo". Sus dudas habían desaparecido; su espíritu recobraba el sosiego: volvía a estar convencido de que, el emprendido, era el único camino cierto para la salvación del alma cubana.

\section{Referencias bibliográficas}

Martí, J. (Ed.). (2007a). Versos sencillos. La Habana, Cuba: Centro de Estudios Martianos y Editorial de Ciencias Sociales.

Martí, J. (2007b). A Gonzalo de Quesada. En J. Martí (Ed.), Obras Completas (pp. 344-345). La Habana, Cuba: Centro de Estudios Martianos y Editorial de Ciencias Sociales.

Martí, J. (2007c). A Gonzalo de Quesada y Benjamín Guerra. En J. Martí (Ed.), Obras Completas, Tomo 4 (pp. 124-125). La Habana, Cuba: Centro de Estudios Martianos y Editorial de Ciencias Sociales.

Martí, J. (2007d). Al General Antonio Maceo. En Centro de Estudios Martianos (Ed.), Obras Completas. Tomo 3. (pp. 210). La Habana, Cuba: Centro de Estudios Martianos.

142 Las tareas del espíritu en José Martí: últimos días en campaña Mayra Beatriz Martínez
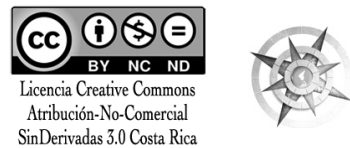
Martí, J. (2007e). A Tomás Estrada. En Centro de Estudios Martianos (Ed.), Obras Completas. Tomo 4. (pp. 130-00). La Habana, Cuba: Centro de Estudios Martianos.

Martí, J. (2007f). A Carmen Mantilla. En Centro de Estudios Martianos (Ed.), Obras Completas. Tomo 20. (pp. 237). La Habana, Cuba: Centro de Estudios Martianos.

Martí, J. (2007g). A Manuel Mercado. En Centro de Estudios Martianos (Ed.), Obras Completas. Tomo 20. (pp. 161-163). La Habana, Cuba: Centro de Estudios Martianos.

Martí, J. (2007h). Diarios de campaña. En Mayra B. Martínez. (Ed.), Edición crítica (pp. 91-91). La Habana, Cuba: Centro de Estudios Martianos.

Martí, J. (2007i). Nuevo libro de José Miguel Macías.. En Centro de Estudios Martianos (Ed.), Obras Completas. Tomo 5.. La Habana, Cuba: Centro de Estudios Martianos.

Martí, J. (2007j). Borradores. En Centro de Estudios Martianos (Ed.), Obras Completas. Tomo 4. (pp. 336). La Habana, Cuba: Centro de Estudios Martianos.

Martí, J. (2007k). Un paseo por la tierra de los ananitas. En La Edad de Oro.. En Centro de Estudios Martianos (Ed.), Obras Completas. Tomo 18. La Habana, Cuba: Centro de Estudios Martianos y Editorial Ciencias Sociales.
Martí, J. (20071). Diarios de Campaña. En Centro de Estudios Martianos (Ed.), Obras completas edición crítica. La Habana, Cuba: Centro de Estudios Martianos.

Martí, J. (2007m). Un funeral chino. En Centro de Estudios Martianos (Ed.), Obras Completas. Tomo 12.. La Habana, Cuba: Centro de Estudios Martianos y Editorial Ciencias Sociales.

Centro de Estudios Martianos. (2007a). A mi María. En J. Martí (Ed.), Obras Completas (pp. 218-218). La Habana, Cuba: Centro de Estudios Martianos.

Centro de Estudios Martianos. (2007b). Nuestras ideas. En J. Martí (Ed.), Obras Completas. La Habana, Cuba: Centro de Estudios Martianos.

Centro de Estudios Martianos. (2007c). Cartas de Martí. En J. Martí (Ed.), Obras Completas. La Habana, Cuba: Centro de Estudios Martianos.

Centro de Estudios Martianos. (2007d). Carta al General Máximo Gómez. En J. Martí (Ed.), Obras Completas. Tomo 1. La Habana, Cuba: Centro de Estudios Martianos.

Centro de Estudios Martianos. (2007e). Carta al General Máximo Gómez. En J. Martí (Ed.), Obras Completas. Tomo 1. La Habana, Cuba: Centro de Estudios Martianos. 
Centro de Estudios Martianos. (2007f). Cartas a Carmen Miyares de Mantilla y sus hijos.. En J. Martí (Ed.), Obras Completas. Tomo 20. La Habana, Cuba: Centro de Estudios Martianos.

Centro de Estudios Martianos. (2007g). Circular a los jefes. En J. Martí (Ed.), Obras Completas. Tomo 4 (pp. 0-0). La Habana, Cuba: Centro de Estudios Martianos.

Cepeda, V. R.. (s.f.). Lo ético cristiano en la obra de José Martí. Matanzas, Cuba: Centro de Enformación Augusto Cotto.

García Marruz, F. (2003). El amor como energía revolucionaria en Martí.. La Habana, Cuba: Centro de Estudios Martianos y Editorial Ciencias Sociales.
Martí, J. (1975). Cuadernos de apuntes. En J. Martí (Ed.), Obras Completas (pp. 344-345). La Habana, Cuba: Centro de Estudios Martianos y Editorial de Ciencias Sociales.

Martí, J. (1985). Manifiesto de Montecristi. La Habana, Cuba: Centro de Estudios Martianos y Editorial Ciencias Sociales.

Martí, J. (2003). Muerte de Emerson. En Centro de Estudios Martianos (Ed.), Obras Completas Edición Crítica. Tomo 9. (pp. 330331). La Habana, Cuba: Centro de Estudios Martianos. Editorial Ciencias Sociales. 